\title{
Enthesitis in psoriatic arthritis - is the clinical evaluation enough?
}

\author{
Daniela-Raluca Decianu', Claudiu C. Popescu ${ }^{2,4}$, Violeta-Claudia Bojinca ${ }^{1,4}$, Mihai Bojinca ${ }^{3,4}$, \\ Andra-Rodica Balanescu ${ }^{1,4}$, Ruxandra Ionescu ${ }^{1,4}$ \\ 1 "Sf. Maria" Clinical Hospital, Bucharest, Romania \\ 2 "Dr. I. Stoia" Rheumatic Disease Center, Bucharest, Romania \\ 3 "Dr. I. Cantacuzino" Clinical Hospital, Bucharest, Romania \\ 4 "Carol Davila" University of Medicine and Pharmacy, Bucharest, Romania
}

\begin{abstract}
Objective. In this study, we aim to evaluate the frequency of enthesitis in psoriatic arthritis (PsA), using musculoskeletal ultrasonography (MSUS) and to determine to what extent it is correlated to clinical spontanous or provoked pain, disease activity and biologic inflammatory markers.

Methods. 320 entheses, belonging to 20 PsA patients, were evaluated clinically and MSUS. For each patient, the medical history form included questions regarding spontaneous pain, targeted to 16 entheseal sites. Then, a thorough enthesis clinical exam was performed, evaluatig pain upon pressure (digital pressure on the enthesis overlying skin). Two Esaote My Lab machines were used, with 6-12/8-18 MHz linear probes. All evaluations were performed by the same clinician/ultrasonographer.

Results. The Achilles, followed by the quadriceps tendons were the most affected by MSUS-detected enthesitis, both in gray scale (GS) (100\%, 75\% respectively) and power Doppler (PD) (40\%, 35\% respectively), while the proximal patellar tendon (35\% GS, $25 \%$ PD), the plantar fascia ( $40 \%$ GS, $25 \%$ PD) and the flexor tendons ( $45 \%$ GS, $25 \%$ PD) were the least affected.

Ultrasound abnormalities were found in up to $68.4 \%$ of the asymptomatic entheses, with high variation between the entheseal sites. The number of ultrasound-detected enthesitis for each patient was significantly correlated with the patient's global assessment for DAPSA and also with the CRP levels, in this lot of patients with high disease activity.

Conclusions. In PsA, the entheses involvement is a central feature, underscored in this study by the high percentages of both GS and PD abnormalities, even in the least affected entheseal sites.

There is a low correlation between clinical symptoms and imaging signs of enthesitis in PsA, which proves the need for an imagistic enthesitis score in the diagnostic process, in order to establish the full extent of the disease and a more personalised therapeutic plan.
\end{abstract}

Keywords: psoriatic arthritis, enthesitis, musculoskeletal ultrasonography

\section{INTRODUCTION}

Spondyloarthritis $(\mathrm{SpA})$ forms a heterogeneous group of diseases with different phenotypes, but with several common features, such as the axial and peripheral joint clinical inflammation, genetic predispositions and trigger factors. The common ground in the pathogenesis of SpA seems to be enthesitis, which further leads to ostheitis, periostitis and osteoproliferation, present in variate proportions in all $\operatorname{SpA}[1,2]$.

The high level of interest on the enthesis in rheumatology is proven by the amount of knowledge achieved on the subject in the last two decades, with the terminology evolving from enthesis to entheseal organ and synovio-entheseal complex [3].

The entheses are fibrocartilaginous structures arising at the insertion sites of tendons, ligaments, joint capsules or nails. The insertional fibrocartilages is generally prone to microdamage, but avascular and lacking immune cells $[3,4]$. Psoriatic arthritis (PsA) patients, with a particularly lower threshold to mechanical stress and a general pro-inflammatory state, easily develop a disproportional degree of inflammation after physiological mechanical stress, with a vessel tissue repair 
responses and vessel ingrowth activation of pro-inflammatory cytokines tumor necrosis factor (TNF) $\alpha$ and interleukin (IL) 17, accompanied by an inflow of innate immune cells [3-5].

In terms of immune pathways, IL-23, with IL-17 and TNF-mediated immune responses have a leading role in triggering enthesitis, while the proliferation process is mainly mediated by IL-22. Exogenous or gut bacteria could also play the role of a trigger factor and unleash an immune reaction, with autoimmunity aiming for fibrocartilage peptides, such as the versican or the bone morphogenetic protein (BMP), in particular in patients with a genetic predisposition, given by the presence of the HLA-B27 antigen. Also, triggered by TNF- $\alpha$ and IL-1, BMP-7 mostly, accompanied by BMP-2 and BMP- 6 are involved in the new bone formation that follows the entheseal inflammation, leading to peripheral and axial bony spurs, enthesophytes and syndesmophytes. Therefore, enthesitis seems to be more a diffuse, continuous process in $\mathrm{SpA}$ and in PsA in particular, as proven by advanced imaging techniques and biopsy results, although initially assumed to be a focal lesion [6-11].

Despite being a central feature in SpA and despite the number of scores elaborated in order to standardize it, enthesitis remains underdiagnosed in the clinical everyday practice.

Convenient and comfortable, little time and cost consuming, with on spot results, ultrasound becomes a very handy bedside tool for detecting and monitoring enthesitis, while a physical evaluation alone has lower sensibility and specificity for SpA. It provides high fidelity image of the enthesis structure and also detailed information regarding the vascularity, transposing into the degree of local inflammation and therefore, disease activity [11-15].

In this context, the objective of this study is to evaluate the frequency of clinical and ultrasound enthesitis in Romanian PsA patients, with highly active disease. Also, we aim to determine to what extent the presence of MSUS GS and PD entheseal abnormalities is correlated to the disease activity, biologic inflammatory markers and to clinical pain, declared during a detailed, targeted medical history or detected in a thorough clinical exam.

\section{METHODS}

\section{Design and patients}

The study included 20 patients fulfilling the CASPAR criteria [16], in the random order of pre- sentation to the Out-patient Clinic or the Department of Internal Medicine and Rheumatology of the "Sfânta Maria" Clinical Hospital or "Dr. I. Cantacuzino" Clinical Hospital, in Bucharest. Patients were recruited between October 2017 and June 2020. All patients suffered from highly active disease (DAPSA > 28) [14] and were naive to biological disease-modifying antirheumatic drugs (bDMARD). The study targeted the clinical and ultrasound involvement in PsA of 16 entheseal sites: Achilles tendon, plantar fascia, qvadriceps tendon, proximal and distal patellar tendon, triceps tendon, extensor and flexor tendons of the hand, all evaluated on both sides. The exclusion criteria consisted of age bellow 18 years, overlap or other chronic inflammatory rheumatic disease, bDMARD therapy, history of knee/ankle/elbow surgery.

Medications which could influence the ultrasound findings were allowed as follows: oral glucocorticoids, if less than $10 \mathrm{mg}$ prednisone equivalent per day and stable in the prior month; non-steroidal anti-inflammatory drugs (NSAIDs), if stable in the prior week, conventional synthetic DMARDs (csDMARDs: sulfasalazine, methotrexate, leflunomide), if stable in the prior month.

The study was approved by the local ethics committee and all patients gave written informed consent.

\section{Patient-reported outcomes}

The patient's global assessment and pain assessment were evaluated on a $10 \mathrm{~cm}$ visual analogue scale (VAS).

The reported pain upon pressure was provoked by applying digital pressure (policis, until nail whitening) on every entheseal site's overlying skin. Careful examination of adjacent joint excluded referred pain.

\section{Clinical examination}

Regarding spontaneous pain, the medical history form contained the question „Do you or did you ever feel pain in this particular spot?" (finger-pointed by the examiner, without touching the overlying skin) for each of the 16 entheseal sites. Pain described after a local traumatic event was disregarded, therefore not noted as a symptom of enthesitis. The responses were noted as 0 ,absence of pain, ever” or 1 , presence of pain, in the present or in the past".

A thorough clinical examination was performed, including a swollen joint count, a tender joint count, 
as included in the DAPSA score [17] and also evaluating the digital pressure-provoked entheseal pain. The responses were noted as 0 ,absence of pain during enthesis pressure” or 1 ,presence of pain during enthesis pressure".

All clinical examinations were done by the same rheumatologist, in parallel with the ultrasound examination.

\section{Ultrasound}

All ultrasound examinations were performed and interpreted by a single rheumatologist, EULAR Level I certified (June 2018, Amsterdam).

Two Esaote My Lab machines were used, with 6-12 MHz and 8-18 MHz linear probes.

Grey scale (GS) abnormalities consisted of: modified tendon structure, increased tendon width, insertional tendon calcification and insertional bone erosion. The presence of any one of the above was noted as a GS-modified enthesis. Considering the superficial location of the studied entheses, the ultrasound evaluation was performed using a high frequency (12-15 MHz).

Power Doppler (PD) was evaluated with a low wall filter (1), a pulse repetition frequency (PRF) of 500 to $1000 \mathrm{~Hz}$, while lowering the gain from a high, artefact value, until the disappearance of the last spot below the cortical line. The identification of any grade of pathological PD signal was noted as present PD signal. Special attention was paid to always maintaining a thick enough layer of gel, to avoid small vessel compression and therefore to avoid a false negative PD signal.

All abnormalities have been confirmed in two perpendicular planes.

\section{Acute phase reactants and disease activity}

Laboratory tests included C-reactive pain (CRP; normal $<5 \mathrm{mg} / \mathrm{dl}$; latex-immunoturbidimetry method using commercially-available kits) and ESR (nor$\mathrm{mal}<20 \mathrm{~mm} / \mathrm{h}$; Westergren method).

The disease activity was measured using DAPSA, a composite score being preferred, for better reliability [17].

\section{Statistics}

Distribution normality was assessed using descriptive statistics, normality and stem-and-leaf plots, and Kolmogorov-Smirnov tests. Differences of continuous variables (e.g. age) among categorical variables (e.g. Achilles enthesitis) were tested with non-parametric tests for independent variables (Mann-Whitney tests). Associations of two dichotomous variables (e.g. ultrasound involvement and RF positivity) were studies with $\chi^{2}$ or Fisher's exact tests. Correlations of continuous variables (e.g. number of enthesitis and DAPSA) were evaluated with Spearman rho indices. The performance of ultrasound compared to clinical examination (for example GS involvement of Achilles tendon insertion and spontaneous pain reported by the patient) was examined using sensitivity, specificity and Cohen's kappa indices (strength of agreement: $<0.2$ poor, $0.21-0.40$ fair, 0.41-0.60 moderate, 0.61-0.80 good and $>0.80$ very good) [18]. The statistical tests were considered significant if $\mathrm{p}<0.05$ and were computed with IBM SPSS Statistics version 22.0 for Windows (Armonk, NY, IBM Corp.).

\section{RESULTS}

\section{General and PsA characteristics}

The study included 20 PsA patients, mostly men (75\%), with a mean age of approximately 45 years, predominantly with oligoarticular phenotype and high disease activity (Table 1).

TABLE 1. General and PSA characteristics $(n=20)$

\begin{tabular}{|c|c|}
\hline men $(\mathrm{n} ; \%)$ & $15(75 \%)$ \\
\hline $\operatorname{age}(\mathrm{y} ;$ mean (SD)) & $44.7(10.5)$ \\
\hline smoking (n; \%) & $2(10 \%)$ \\
\hline urban dwelling ( $\mathrm{n} ; \%)$ & $15(75 \%)$ \\
\hline oligoarticular PsA (n; \%) & $12(60 \%)$ \\
\hline polyarticular PsA (n; \%) & $8(40 \%)$ \\
\hline PsA duration (y; median (IQR)) & $2.0(4.8)$ \\
\hline dactylitis (n; \%) & $6(30 \%)$ \\
\hline nail dystrophy (n; \%) & $14(70 \%)$ \\
\hline PtGA (VAS; mean (SD)) & $7.9(1.0)$ \\
\hline PtPA (VAS; mean (SD)) & $8.2(1.0)$ \\
\hline DAPSA (mean (SD)) & $38.6(9.6)$ \\
\hline$C R P(\mathrm{mg} / \mathrm{l} ;$ mean (SD) & $51.5(21.5)$ \\
\hline ESR (mm/h; mean (SD)) & $73(25)$ \\
\hline $\operatorname{cs} D M A R D s(\mathrm{n} ; \%)$ & $16(80 \%)$ \\
\hline glucocorticoids (n; \%) & $6(30 \%)$ \\
\hline
\end{tabular}

CRP - C-reactive protein (normal $<5 \mathrm{mg} / \mathrm{l}$ ); csDMARDs - conventional synthetic disease-modifying anti-rheumatic drugs; DAPSA - Disease Activity in PSoriatic Arthritis; ESR - erythrocyte sedimentation rate (normal < $20 \mathrm{~mm} / \mathrm{h}$ ); IQR - interquartile range; PsA - psoriatic arthritis; PtGA - patient's global assessment; PtPA - patient's pain assessment; SD - standard deviation; VAS - visual analogue scale (0-10); y - years.

\section{Enthesitis prevalence}

Clinically, the most affected site on clinical examination was Achilles tendon enthesitis (80\%), fol- 
lowed by quadriceps tendon enthesitis $(60 \%$; Table 2), a pattern which was followed by ultrasound findings (the most frequent GS and PD involved structures were Achilles and quadriceps tendons).

TABLE 2. Clinical and ultrasound enthesitis prevalence by site $(n=20)$

\begin{tabular}{|l|c|c|c|c|}
\hline $\begin{array}{l}\text { a) clinical } \\
\text { involvement }\end{array}$ & \multicolumn{2}{|c|}{$\begin{array}{c}\text { symptomatic } \\
\text { (spontaneous) }\end{array}$} & \multicolumn{2}{c|}{$\begin{array}{c}\text { symptomatic } \\
\text { (examination) }\end{array}$} \\
\hline unilateral & bilateral & unilateral & bilateral \\
\hline Achilles' tendon & $8(40 \%)$ & $1(5 \%)$ & $16(80 \%)$ & $5(25 \%)$ \\
\hline plantar fascia & $4(20 \%)$ & $0(0 \%)$ & $7(35 \%)$ & $2(10 \%)$ \\
\hline $\begin{array}{l}\text { quadriceps } \\
\text { tendon }\end{array}$ & $10(50 \%)$ & $5(25 \%)$ & $12(60 \%)$ & $7(35 \%)$ \\
\hline $\begin{array}{l}\text { proximal patellar } \\
\text { tendon }\end{array}$ & $5(25 \%)$ & $1(5 \%)$ & $6(30 \%)$ & $2(10 \%)$ \\
\hline $\begin{array}{l}\text { distal patellar } \\
\text { tendon }\end{array}$ & $3(15 \%)$ & $2(10 \%)$ & $7(35 \%)$ & $3(15 \%)$ \\
\hline triceps tendon & $3(15 \%)$ & $0(0 \%)$ & $7(35 \%)$ & $2(10 \%)$ \\
\hline flexor tendons & $3(15 \%)$ & $0(0 \%)$ & $6(30 \%)$ & $0(0 \%)$ \\
\hline extensor tendons & $5(5 \%)$ & $0(0 \%)$ & $7(35 \%)$ & $2(10 \%)$ \\
\hline $\begin{array}{l}\text { b) ultrasound } \\
\text { involvement }\end{array}$ & \multicolumn{2}{|c|}{ involvement } & \multicolumn{2}{c|}{ involvement } \\
\hline & unilateral & bilateral & unilateral & bilateral \\
\hline $\begin{array}{l}\text { Achilles' tendon } \\
20\end{array}$ & $13(65 \%)$ & $8(40 \%)$ & $3(15 \%)$ \\
\hline plantar fascia & $8(40 \%)$ & $3(15 \%)$ & $5(25 \%)$ & $0(0 \%)$ \\
\hline $\begin{array}{l}\text { quadriceps } \\
\text { tendon }\end{array}$ & $15(75 \%)$ & $11(55 \%)$ & $7(35 \%)$ & $2(10 \%)$ \\
\hline $\begin{array}{l}\text { proximal patellar } \\
\text { tendon }\end{array}$ & $7(35 \%)$ & $3(15 \%)$ & $5(25 \%)$ & $1(5 \%)$ \\
\hline $\begin{array}{l}\text { distal patellar } \\
\text { tendon }\end{array}$ & $14(70 \%)$ & $7(35 \%)$ & $4(20 \%)$ & $2(10 \%)$ \\
\hline triceps tendon & $10(50 \%)$ & $7(35 \%)$ & $4(20 \%)$ & $0(0 \%)$ \\
\hline flexor tendons & $9(45 \%)$ & $0(0 \%)$ & $5(25 \%)$ & $0(0 \%)$ \\
\hline extensor tendons & $10(50 \%)$ & $3(15 \%)$ & $6(30 \%)$ & $2(10 \%)$ \\
\hline
\end{tabular}

GS - grey scale; $P D$ - power Doppler

\section{Correlations with clinical PsA variables}

Regarding the Achilles tendon, compared to patients who did not complain of spontaneous pain, those who reported pain in any Achilles tendon insertion also reported a significantly higher pain assessment for the DAPSA score (a median of 8 compared to a median of $7, p=0.047$ ). Also, compared to patients with normal bilateral clinical examination of Achilles tendons, those with pain elicited by pressure at both Achilles tendon insertions had significantly higher median CRP $(78.8 \mathrm{mg} / \mathrm{l}$ compared to $47.6 \mathrm{mg} / \mathrm{l} ; \mathrm{p}=0.008)$ and ESR $(98 \mathrm{~mm} / \mathrm{h}$ compared to $61 \mathrm{~mm} / \mathrm{h} ; \mathrm{p}=0.042$ ). The prevalence of bilateral GS involvement of Achilles tendons was significantly higher among men (80\%) compared to women $(20 \% ; p=0.031) .19(47.5 \%)$ of the 40 evaluated Achilles tendon insertions were normal on physical examination. From the total of 19 clinically normal Achilles entheses, 13 (68.4\%) had GS involvement and $1(5.3 \%)$ had PD enthesitis.

All patients with positive PD in at least one plantar fascia had oligoarticular PsA, while only 53.3\% of those without positive PD in at least one plantar fascia had oligoarticular PsA $(p=0.035)$. The prevalence of oligoarticular PsA among patients with positive clinical examination of any plantar fascia was significantly higher than the prevalence of this disease phenotype among patients with no objective pain of plantar fasciae (100\% compared to $38.5 \%$; p $=0.015)$. There were no smokers among patients without spontaneous plantar fascia pain, while $50 \%$ of those with spontaneous plantar fascia pain were active smokers $(p=0.032)$. From the 40 evaluated plantar fasciae, $31(77.5 \%)$ were normal on physical examination, of which $3(9.7 \%)$ had GS involvement of the entheses.

With regard to the quadriceps tendon, patients who reported spontaneous pain of any quadriceps tendon insertion had significantly higher median patient-reported pain for DAPSA (9 compared to 7; $\mathrm{p}=0.035)$ and ESR $(88 \mathrm{~mm} / \mathrm{h}$ compared to $54 \mathrm{~mm} / \mathrm{h}$; $\mathrm{p}=0.007)$, than those without spontaneous symptoms. Compared to patients with normal examinations of quadriceps tendons insertions, those with pain in any quadriceps tendon insertion on physical examination had significantly higher median ESR ( $88 \mathrm{~mm} / \mathrm{h}$ compared to $58 \mathrm{~mm} / \mathrm{h} ; \mathrm{p}=0.031) .21$ $(52.5 \%)$ of the quadriceps tendon insertions were clinically normal, amongst which 8 (38.1\%) had GS entheseal abnormalities.

Patients with GS involvement of any proximal patellar tendon insertion reported a significantly higher global assessment for DAPSA ( 9 compared to $7 ; \mathrm{p}=0.046$ ), compared to those without GS involvement of proximal patellar insertions. Of the 40 evaluated proximal patellar tendon insertions, 32 $(80 \%)$ were normal on physical examination, of which 5 (15.6\%) had GS involvement, while regarding the distal patellar tendon insertions, 30 (75\%) were clinically normal, of which $15(50 \%)$ had GS signs of enthesitis.

On the subject of the triceps tendon, patients with bilateral GS involvement had a significantly higher median disease duration (5.0 years compared to 2.5 years; $\mathrm{p}=0.046)$ and median CRP $(67.2 \mathrm{mg} / \mathrm{l} \mathrm{com-}$ pared to $44.7 \mathrm{mg} / 1 ; \mathrm{p}=0.011$; Figure 1a). Also, patients who reported pain in at least one triceps insertion had a significantly lower median disease 
duration ( 0.5 years compared to 4.5 years; $\mathrm{p}=0.040$ ). $31(77.5 \%)$ of the triceps entheses were normal on physical examination, 9 (29\%) of which had GS abnormalities.

Regarding the flexor tendons, patients with at least one GS involvement of flexor enthesitis had significantly higher median CRP $(67.2 \mathrm{mg} / \mathrm{l}$ compared to $40.3 \mathrm{mg} / \mathrm{l} ; \mathrm{p}=0.020$; Figure $1 \mathrm{~b}$ ), while those with at least one site of flexor enthesitis with PD had a significantly higher median DAPSA score (39.3 compared to $29.5 ; \mathrm{p}=0.015)$. Of the 40 scanned flexor tendon insertions, $34(85 \%)$ were normal on physical examination, $6(17.6 \%)$ of which had ultrasound GS involvement and 1 (2.9\%) PD signal.

Concerning the extensor insertions, patients with at least one extensor enthesitis with PD had signifi- cantly higher median CRP $(72.8 \mathrm{mg} / 1$ compared to $46.1 \mathrm{mg} / 1 ; \mathrm{p}=0.020$; Figure $1 \mathrm{c})$, similar to those with at least one extensor enthesitis with pain on clinical examination, who also had significantly higher median CRP $(66.8 \mathrm{mg} / \mathrm{l}$ compared to 44.7 $\mathrm{mg} / \mathrm{l} ; \mathrm{p}=0.024$; Figure $1 \mathrm{~d}) .31$ (77.5\%) of the evaluated extensor tendon insertions were clinically normal, of which in 7 (22.6\%) ultrasound GS abnormalities were detected and in $2(6.5 \%)$, PD signal.

The extent of enthesitis involvement was directly proportional with activity indices, as indicated by the significant correlation of the number of GS and PD enthesitis with CRP (Figure 2, left pane) and DAPSA (Figure 2 right pane).

The number of ultrasound-detected enthesites (calculated as the sum of GS involvement of investi-
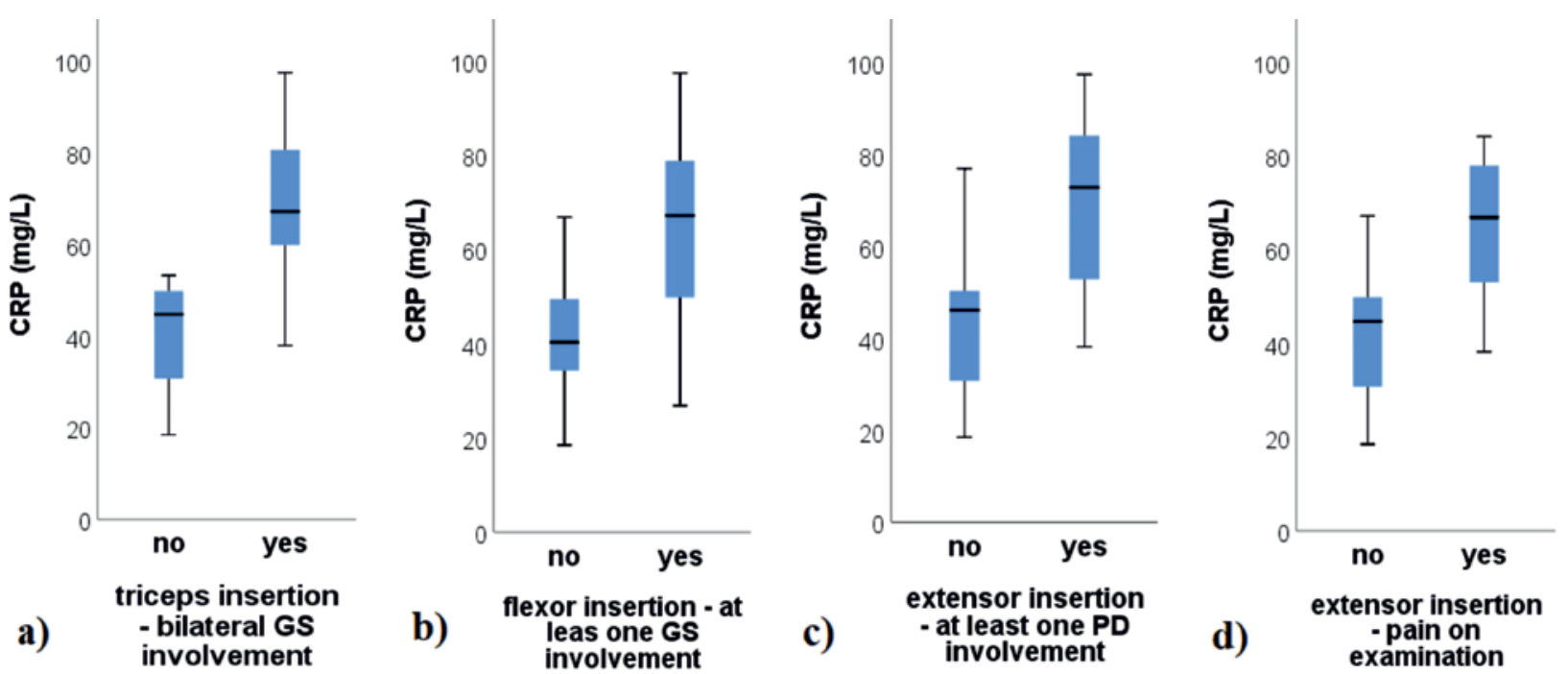

FIGURE 1. Higher median CRP levels in patients with corresponding enthesitis on ultrasound or clinical examination
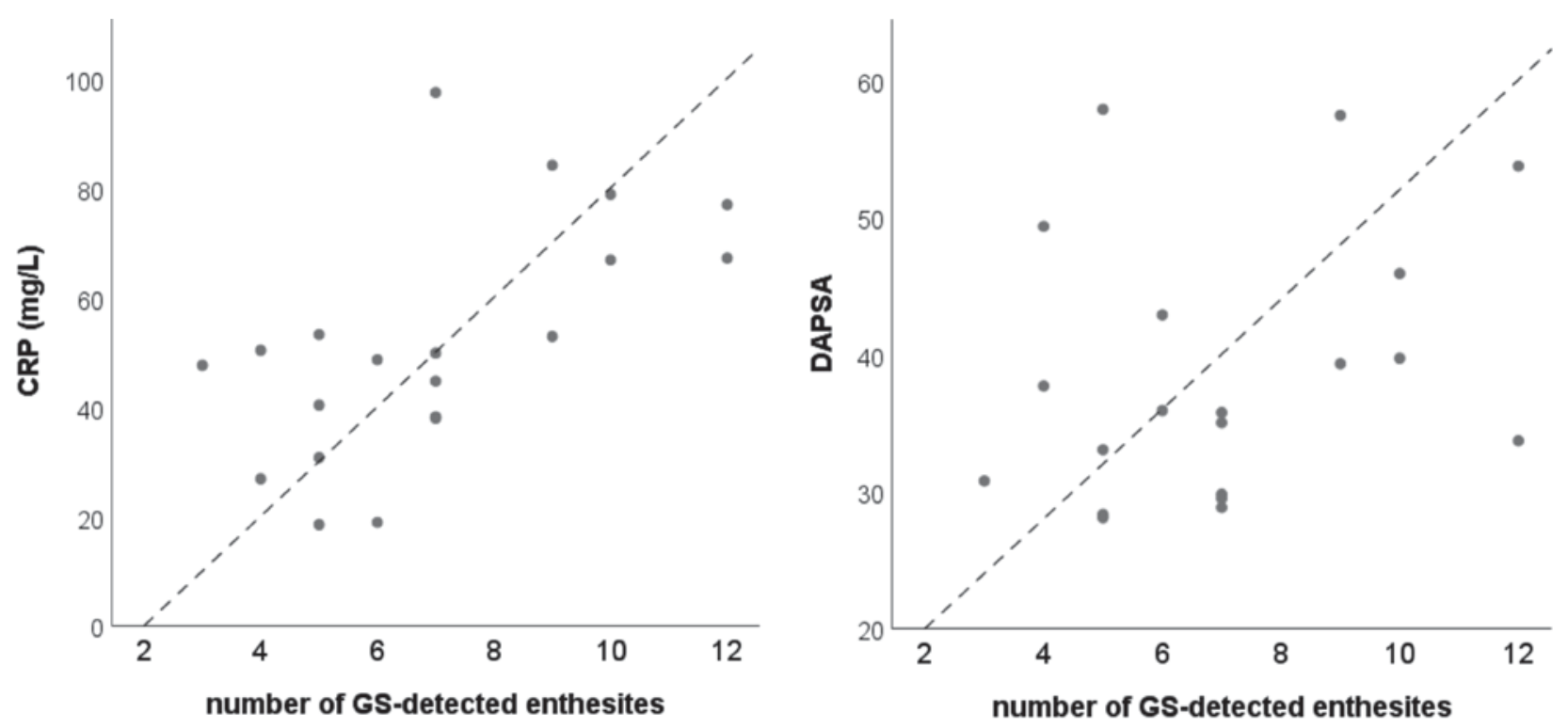

FIGURE 2. Correlations of the number of ultrasound-detected enthesites with disease activity indices (CRP and DAPSA) 
gated sites) was significantly and positively correlated with patient's global assessment for DAPSA $($ rho $=0.481 ; p=0.032)$ and CRP levels (rho $=0.615$; $\mathrm{p}=0.004)$.

GS and PD involvement of evaluated enthesitis sites did not exhibit significant correlations with age and disease duration.

Generally, the best performance of clinical and ultrasound examination was noticed with regard to the evaluation of quadriceps, proximal patellar and triceps tendons (Table 3), with good and very good agreement between the two methods. Conversely, the lowest performance of clinical and ultrasound examination was noticed for Achilles, distal patellar and flexor tendons, with non-significant agreement indices.

TABLE 3. Performance and agreement of clinical and ultrasound evaluation of enthesitis $(n=20)$

\begin{tabular}{|c|c|c|c|c|}
\hline & $\mathrm{Se}$ & Sp & kappa & $p$ \\
\hline AT GS-SSP & $40.0 \%$ & - & - & - \\
\hline AT GS-SPR & $80.0 \%$ & - & - & - \\
\hline AT PD-SSP & $50.0 \%$ & $66.7 \%$ & 0.17 & 0.456 \\
\hline AT PD-SPR & $50.0 \%$ & $100 \%$ & 0.29 & 0.068 \\
\hline PF GS-SSP & $75.0 \%$ & $68.8 \%$ & 0.30 & 0.110 \\
\hline$P F G S-S P R$ & $85.7 \%$ & $84.6 \%$ & 0.68 & 0.002 \\
\hline PF PD-SSP & $50.0 \%$ & $81.3 \%$ & 0.29 & 0.197 \\
\hline$P F P D-S P R$ & $71.4 \%$ & $100.0 \%$ & 0.77 & $<0.001$ \\
\hline QC GS-SSP & $100.0 \%$ & $50.0 \%$ & 0.50 & 0.010 \\
\hline$Q C G S-S P R$ & $100.0 \%$ & $62.5 \%$ & 0.67 & 0.002 \\
\hline$Q C P D-S S P$ & $60.0 \%$ & $90.0 \%$ & 0.50 & 0.019 \\
\hline$Q C P D-S P R$ & $58.3 \%$ & $100.0 \%$ & 0.53 & 0.007 \\
\hline$P P$ GS-SSP & $80.0 \%$ & $80.0 \%$ & 0.53 & 0.015 \\
\hline$P P$ GS-SPR & $83.3 \%$ & $85.7 \%$ & 0.66 & 0.003 \\
\hline$P P P D-S S P$ & $100.0 \%$ & $100.0 \%$ & 1.00 & $<0.001$ \\
\hline$P P P D-S P R$ & $83.3 \%$ & $93.3 \%$ & 0.88 & $<0.001$ \\
\hline DP GS-SSP & $33.3 \%$ & $23.5 \%$ & 0.17 & 0.133 \\
\hline DP GS-SPR & $71.4 \%$ & $30.8 \%$ & 0.02 & 0.919 \\
\hline$D P P D-S S P$ & $66.7 \%$ & $88.2 \%$ & 0.48 & 0.028 \\
\hline DP PD-SPR & $42.9 \%$ & $92.3 \%$ & 0.39 & 0.061 \\
\hline TC GS-SSP & $66.7 \%$ & $52.9 \%$ & 0.10 & 0.531 \\
\hline TC GS-SPR & $85.7 \%$ & $69.2 \%$ & 0.50 & 0.019 \\
\hline$T C P D-S S P$ & $100.0 \%$ & $94.1 \%$ & 0.83 & $<0.001$ \\
\hline$T C P D-S P R$ & $57.1 \%$ & $100.0 \%$ & 0.63 & 0.002 \\
\hline FX GS-SSP & $66.7 \%$ & $58.8 \%$ & 0.14 & 0.413 \\
\hline FX GS-SPR & $50.0 \%$ & $57.1 \%$ & 0.06 & 0.769 \\
\hline FX PD-SSP & $66.7 \%$ & $82.4 \%$ & 0.39 & 0.071 \\
\hline$F X P D-S P R$ & $66.7 \%$ & $92.9 \%$ & 0.63 & 0.005 \\
\hline EX GS-SSP & $80.0 \%$ & $60.0 \%$ & 0.30 & 0.121 \\
\hline EX GS-SPR & $71.4 \%$ & $61.5 \%$ & 0.30 & 0.160 \\
\hline EX PD-SSP & $80.0 \%$ & $86.7 \%$ & 0.63 & 0.005 \\
\hline$E X P D-S P R$ & $71.4 \%$ & $92.3 \%$ & 0.66 & 0.003 \\
\hline
\end{tabular}

AT-Achilles tendon; DP - distal patellar tendon; EX - extensor tendons; FX-flexor tendons; GS - gray scale; $P D$ - power Doppler; $P F$ - plantar fascia; $P P$ - proximal patellar tendon; $Q C$ - quadriceps tendon; Se - sensitivity; SP - specificity; SSP - spontaneous pain; SPR - pain on pressure (clinical examination); TC - triceps tendon

\section{DISCUSSIONS}

The rate of ultrasound-detected enthesitis was much higher than that observed clinically, a result that was predictable to some extent, considering the literature data [10,13,14,19-21]. Using ultrasound, signs of enthesitis were detected in up to $68.4 \%$ of the clinically normal entheses, asymptomatic after both medical history and physical examination. In variable percentages, in all of the evaluated tendon insertions, enthesitis had a higher rate of detection by ultrasound than by clinical evaluation alone. Lower rates of asymptomatic signs of enthesitis and therefore a better correlation between clinical and ultrasound results were found in points of high mechanical stress and pressure, like the plantar fascia, where it is more likely for an entheseal calcification do cause pain.

A much better correlation was found with the inflammation markers and the composite index specific to the disease. The number of ultrasound-detected enthesitis was significantly correlated with the patient's global assessment for DAPSA, while in different tendons, the presence of pain, GS or PD abnormalities were correlated with a higher DAPSA score. This finding is in agreement with existing data associating enthesitis with a more active disease, more pain, a greater overall disease burden of PsA and worse prognostic outcomes [1,22,23]. Pain, both spontaneous and elicited by pressure, was significantly correlated with higher median biologic inflammatory markers. Also, a bilateral involvement was correlated with higher CRP levels. Considering that a highly active disease was one of the inclusion criteria, a comparison with the ultrasound findings in a low disease activity patient is an obvious checkpoint further along this study, but at this point, unavailable.

Given the limited number of patients, no significant correlation was found between ultrasound-defined enthesitis and age or disease duration. Only triceps GS signs of enthesitis were found to be correlated to a higher disease duration, but the olecranon process is also known to be prone to high mechanical stress and repeated trauma [4,24].

Regarding the symptoms, in some entheses, like the triceps insertion, spontaneous pain correlated with a lower disease duration, suggesting better reliability on the patient's reported outcomes in the first years of the disease, rather than later, when possible degenerative or psychosocial factors could be added. 
According to recent studies, the prevalence of fibromyalgia has been reported in $16-22 \%$ of PsA patients, leading to significantly higher patient-reported outcomes and DAPSA score in patients with concomitant fibromyalgia $[25,26]$. Objective pain at clinical examination correlated better with the oligoarticular form of PsA.

The limitations of the study are mostly with reference to the small number of PsA patients at this point in the study. For better correlations regarding more tendons and the entire lot, more patients are being enrolled in the study. Also, the patients are evaluated dynamically, after undergoing therapy and obtaining variable rates of lower disease activity than at baseline.

The possible pre-existence of degenerative entheseal abnormalities, mostly GS, could be falsely interpreted in the context of PsA. A further research direction on this subject is examining enthesitis patterns in healthy subjects.

This study will continue prospectively, evaluating the dynamics of the ultrasound and clinical abnormalities after 6 months and 12 months of bDMARD versus non-bDMARD therapy, compared to baseline.

\section{CONCLUSIONS}

Enthesitis is a relatively unique, hallmark feature of PsA, preceding synovitis and nail involvement in the pathogenesis of PsA. Clinical examination alone, even when it is positive, offers clinicians low amount of information regarding structural abnormalities and degree of activity, imaging techniques, such as ultrasound and magnetic resonance imaging (MRI),

\section{REFERENCES}

1. Kaeley GS, Eder L, Aydin SZ, et al. Enthesitis: A hallmark of psoriatic arthritis. Semin Arthritis Rheum. 2018;48(1):35-43.

2. Ionescu R. Spondilartropatii seronegative. In Esenţialul în reumatologie. Ed Amaltea, 2006; pp. 281-293.

3. Benjamin M, McGonagle D. The enthesis organ concept and its relevance to the spondyloarthropathies. Adv Exp Med Biol. 2009;649:57-70.

4. Araujo EG, Schett G. Enthesitis in psoriatic arthritis (Part 1): Pathophysiology. Rheumatology (Oxford). 2020;59(1):i10-i14.

5. Opris-Belinski D. Conceptul de spondiloartrite. In Reumatologie Curs universitar. Ed Universitara "Carol Davila”, 2017; pp. 179-181.

6. McGonagle D, Stockwin L, Isaacs J, Emery P. An enthesitis based model for the pathogenesis of spondyloarthropathy: additive effects of microbial adjuvant and biomechanical factors at disease sites. $J$ Rheumatol. 2001;28:2155-2159.

7. McGonagle D, Marzo-Ortega H, O'Connor P, et al. Histological assessment of the early enthesitis lesion in spondyloarthropathy. Ann Rheum Dis. 2002;61:534-537. having the capacity of completing a well conducted medical history and clinical examination. In this direction, ultrasound has better availability in the clinical, everyday practice.

The correlation between ultrasound GS and/or PD enthesitis and pain is low, especially in the Achilles tendon. The means of measuring the disease activity correlate better to the extent of enthesitis for each patient, in this lot of high disease activity PsA patients, but a comparison with the ultrasound entheseal patterns in patients with low disease activity is due.

The increased rates of ultrasound-detected entheseal involvement, both GS and PD, compared to the clinical findings, either spontaneous or elicited tenderness, even in the least affected entheseal sites, underscores the need for an imagistic enthesitis score in the diagnostic process.

This would be useful not only in order to establish the full extent of the disease, but also to design a more personalized therapeutic plan, even more so considering the need to distinguish between the disease-related patient-reported outcomes and the possible intricate degenerative of psychosomatic pathology.

\section{Acknowledgements}

This paper and the research behind it would not have been possible without the exceptional support of the Rheumatology physicians and trainees from the Internal Medicine and Rheumatology Departments of the "Sf. Maria" Clinical Hospital and "Dr. I. Cantacuzino" Clinical Hospital, in Bucharest, who referred patients that matched the study inclusion criteria.

Conflict of interest: none declared Financial support: none declared

8. Kehl AS, Corr M, Weisman MH, et al. Enthesitis - New Insights Into Pathogenesis, Diagnostic Modalities, and Treatment. Arthritis Rheumatol. 2016;68(2):312-322.

9. Weiss PF. Evaluation and treatment of enthesitis-related arthritis. Curr Med Lit Rheumatol. 2013;32:33-41.

10. Kaeley GS. Enthesitis in psoriatic arthritis (Part 2): Imaging Rheumatology (Oxford). 2020;59(1):i15-i20.

11. Mease P. Enthesitis in psoriatic arthritis (Part 3 ): Clinical assessment and management. Rheumatology (Oxford). 2020;59(1):i21-i28.

12. D’Agostino MA, Olivieri I. Enthesitis. Best Pract Res Clin Rheumatol. 2006;20:473-486.

13. Ruta S, Gutierrez M, Pena C, et al. Prevalence of subclinical enthesopathy in patients with spondyloarthropathy: An ultrasound study. J Clin Rheumatol. 2011;17:18-22.

14. D'Agostino MA, Said-Nahal R, Hacquard-Bouder $C$, et al. Assessment of peripheral enthesitis in the spondylarthropathies by 
ultrasonography combined with power Doppler: a cross-sectional study. Arthritis Rheum. 2003;48:523-533.

15. Naredo E, Moller I, de Miguel E, et al. High prevalence of ultrasonographic synovitis and enthesopathy in patients with psoriasis without psoriatic arthritis: A prospective case-control study. Rheumatology (Oxford). 2011;50:1838-1848.

16. Taylor W, Gladman D, Helliwell P, et al. Classification criteria for psoriatic arthritis: development of new criteria from a large international study. Arthritis Rheum. 2006;54(8):2665-2673.

17. Schoels MM, Aletaha $D$, Alasti $F$, et al. Disease activity in psoriatic arthritis (PsA): defining remission and treatment success using the DAPSA score. Ann Rheum Dis. 2016;75:811-818.

18. McHugh ML. Interrater reliability: The kappa statistic. Biochem Med. (Zagreb). 2012;22 (3):276-282.

19. Bandinelli F, Prignano F, Bonciani D, et al. Ultrasound detects occult entheseal involvement in early psoriatic arthritis independently of clinical features and psoriasis severity. Clin Exp Rheumatol. 2013; 31: 219-224.

20. Kristensen S, Christensen JH, Schmidt EB, et al. Assessment of enthesitis in patients with psoriatic arthritis using clinical examination and ultrasound. Muscles Ligaments Tendons J. 2016; 6(2): 241-247.

21. Klauser AS, Wipfler E, Dejaco C, et al. Diagnostic values of history and clinical examination to predict ultrasound signs of chronic and acute enthesitis. Clin Exp Rheumatol. 2008;26:548-553.
22. Polachek A, Li S, Chandran V, Gladman DD. Clinical Enthesitis in a Prospective Longitudinal Psoriatic Arthritis Cohort: Incidence, Prevalence, Characteristics, and Outcome. Arthritis Care Res. 2017;69:1685-1691.

23. Mease PJ, Karki C, Palmer JB, et al. Clinical Characteristics, Disease Activity, and Patient-Reported Outcomes in Psoriatic Arthritis Patients With Dactylitis or Enthesitis: Results From the Corrona Psoriatic Arthritis/Spondyloarthritis Registry. Arthritis Care Res. 2017;69:1692-1699.

24. Di Matteo A, Filippucci E, Cipolletta E, et al. Entheseal Involvement in Asymptomatic Healthy Subjects: Prevalence and Distribution of the Ultrasound Elementary Lesions of Enthesitis, with a Particular Focus on Those Indicating "Active" Inflammation [abstract]. Arthritis Rheumatol. 2018;70(10).

25. Brikman S, Furer V, Wollman J, et al. The Effect of the Presence of Fibromyalgia on Common Clinical Disease Activity Indices in Patients with Psoriatic Arthritis: A Cross-sectional Study. J Rheumatol. 2016;43(9):1749-1754.

26. Mease PJ. Fibromyalgia, a missed comorbidity in spondyloarthritis: Prevalence and impact on assessment and treatment. Curr Opin Rheumatol. 2017;29(4):304-310. 